\title{
Starreveld scoring method and constipation
}

\author{
Viroj Wiwanitkit
}

Received: 5 July 2010 /Revised: 19 July 2010 / Accepted: 31 October 2010 /Published online: 3 December 2010

(C) Springer-Verlag 2010

Sir,

I read the recent report by Kokke et al. [1] with great interest. Kokke et al. [1]. concluded that "The Starreveld scoring method to assess faecal loading on a plain abdominal radiograph is of limited value in the diagnosis of childhood constipation". I would like to share ideas on this work. First, there are several causes of constipation (functional nonretentive faecal incontinence, or functional or organic constipation) that might lead to differences in the scoring result. To give clear information on the usefulness of a scoring system, the study should completely detail and group the subjects based on causes of constipation that can be seen in a previous referenced publication [2]. Second, there might be some bias in the design of this work. It is not common to use four observers as in this work. In general, three observers are used in this kind of assessment [2]. In

V. Wiwanitkit $(\bowtie)$

Wiwanitkit House,

Bangkhae,

Bangkok, Thailand 10160

e-mail: wviroj@yahoo.com addition, it is required to test the basic abilities of each observer before starting the study. Differences in experience are reported to result in different resultant scoring in this kind of assessment [3]. Third, I have a question: If the cutoff value is adjusted to different age-specific paediatric groups, will the scoring system be acceptable or not?

Conflict of interest None.

\section{References}

1. Kokke FT, Sittig JS, de Bruijn A et al (2010) Starreveld scoring method in diagnosing childhood constipation. Pediatr Radiol 40:1789-1793

2. de Lorijn F, van Rijn RR, Heijmans J et al (2006) The Leech method for diagnosing constipation: intra- and interobserver variability and accuracy. Pediatr Radiol 36:43-49

3. Jackson CR, Lee RE, Wylie AB et al (2009) Diagnostic accuracy of the Barr and Blethyn radiological scoring systems for childhood constipation assessed using colonic transit time as the gold standard. Pediatr Radiol 39:664-667 